\title{
CAN HELICICULTURE ACT AS A TOOL FOR EDIBLE LAND SNAILS' NATURAL POPULATIONS' MANAGEMENT IN ROMANIA?
}

\author{
Voichita, GHEOCA \\ Lucian Blaga University of Sibiu, ROMANIA, vgheoca@yahoo.com
}

\begin{abstract}
Edible land snails are intensively exploited and the management of natural populations is a complex issue due the variety of factors involved. Two species of the genus Helix are present in our country, Helix pomatia and Helix lucorum, both of them collected since 1956. Although current legislation regulates the exploited amount and the dimension of collected snails, the exploitable amount is not assessed using appropriate ecological studies. The farming of edible snails has evolved in Romania especially during the period 2004-2008, the first farms being financed by the SAPARD Project. The inappropriate documentation on the matter of snail farming had lead to a quick failure of this practice in Romania. It is unlikely that snail farming will replace collection on short or medium term, but obtaining reasonable quantities of snails in snail farms could help to reduce their exploitation in nature to an acceptable level and keep a sustainable exploitation.
\end{abstract}

KEY WORDS: edible land snails, natural population management, snail farming

\section{INTRODUCTION}

Animal resource's exploitation in economic purposes is a major current issue all over the world. An important element concerning the management of species with economic value is to assure a sustainable exploitation from an ecologic, economic and genetic point of view, to establish extraction levels that allow the population's stability being therefore able to assure the continuity of exploitation. Sustainability has come to be seen as an interaction of social, economic and environmental dimensions of human behavior (Adams, 2006). Among many invertebrate species, edible land snails are intensively exploited and the management of natural populations is a complex issue due to the variety of factors involved.

Although edible land snails' use in Europe has a rich history that can be traced from prehistory trough the Roman Empire and the Middle Age, with a whole register of uses in alimentation, pharmacy or medicine (Cranga and Cranga, 1997; Bonnenheim, 2005; Duhart, 2009), their intensive exploitation begun in the XIX-th Century in France. At the start of the XX-th Century France was already unable to supply a market in continuous development, appealing to the countries of Western Europe. Subsequently, the development of agriculture, habitat fragmentation and degradation, altered the state of edible snail Helix pomatia in France and then in the rest of Western Europe. The explosive growth in the consumption of snails during the last decades, as well as new non-alimentary uses in medicine, pharmacy and cosmetics have intensified the collection of these animals (Dwek et al., 2001; Brooks and Leathem, 1991; Reza Arab, 2010; Lanzman-Petitthory, 2001; Dominguez Valdes-Hevia et al, 2012).

Starting with 1979, legislative measures were taken for this species, initially in France, and then extended in the entire European Union and the exploitation moved toward the eastern European countries. Helix pomatia is listed in Annex III of Bern Convention and Annex $\mathrm{V}$ of the Directive
92/43/EEC on the conservation of natural habitats and wild fauna and flora (Habitats Directive), appendices on vulnerable species of animals whose exploitation must be subject to management. As a result, throughout the European Union, in the absence of restrictive regulations which prohibit commercial collection, this is made only on authorizations basis, which stipulates the amount that can be collected by individual collectors, the collection area and species (Gheoca, 2013). Collecting land snails is more an activity comparable to the harvest of vegetal resources than with the exploitation of other animals. Unlike fishing or hunting that require a permit or a membership making it easy to identify the practitioners, the harvest of snails can be performed by any interested person. From about twenty European edible land snail species, the Helix genus represents over $70 \%$ of the world snail market. Two species of the genus are present in our country, Helix pomatia and Helix lucorum, the first one with a wide distribution, while $H$. lucorum is limited to the southern part of Romania. Due to its gastronomic qualities, H. pomatia is the most appreciated and, therefore, the most intensely exploited in the wild.

Despite the fact that we only have at this moment an incomplete image regarding the exploitation of edible land snails and especially of Helix pomatia, the actual evidences give rise to some concerns about the species' future.

\section{EDIBLE LAND SNAILS' EXPLOITATION IN ROMANIA}

\subsection{Past and present regulations}

Some practice of consuming snails in Romania can only be connected to small areas from Banat and Oltenia, and to embracement of the French culture at the beginning of the twentieth Century, without becoming a tradition. Responding to the increased European demand, in Romania land snails have been collected for export since 1956. The only regulations at that time concerned the shell diameter (28-36 $\mathrm{mm}$ ) and the season of exploitation (April to June). In this way, the exploited amount and the conservation of big adult 
snails (over $36 \mathrm{~mm}$ shell diameter) allowed the populations' maintenance. In the absence of a legal framework during 1990-1994, Romania experienced an outbreak of snail exports, including meat processed in plants set up mostly in Transylvania by several foreign companies. After signing the Convention on the conservation of wildlife and natural habitats in Europe in 1993 (the Berne Convention adopted in 1979), starting in 1994 the export of live or processed gastropods became possible only with the permission of local environment protection agencies. This regulation has led to a drastic decrease of exported amount. This first step was followed by several regulations completing the legal framework for this activity, thus in 2001 a procedure for harvesting activities, capture and/or acquisition and domestic marketing and export of plant and animal wildlife and their importation was adopted. Order 410/2008 replaced this procedure for the approval of the authorization procedure for harvesting, capture and/or purchase and/or internal marketing, export or import of mine flowers, fossils, plants and animals. The new legislation also regulates the size of collected snails, being allowed to collect all the animals with the shell diameter over greater $30 \mathrm{~mm}$. Although this value is generally the one imposed in most European countries, it enables the removal of a large amount of adult individuals from the population, namely all individuals that are found. Considering that the collection is performed in April-May, before the development of vegetation, they can be easily identified.

\subsection{Collecting snails in Romania - a social issue}

The development of snail collection from the wild relies on two major conditions, the availability of resource and the existence of collectors. Concerning the resource, our country has a climate and relief favorable for the presence of the most valuable edible land snail species, Helix pomatia, whose distribution covers the entire country. In contrast to other species of this genus, $H$. pomatia requires lower temperatures and higher amount of humidity, making the species most abundant in the submountain and hilly areas. The species' abundance and increased demand on the European market made it the most important species exploited in Romania. Another edible species present in our country is H. lucorum, distributed only in south of Romania, and, in consequence, less important in the exported amount.

The second condition to fulfill is the existence of collectors, meaning people interested in collecting snails and not involved in permanent activities (unemployed). The scarcity of the collectors was one of the reasons for giving up the collection in Western Europe. In France, for instance, the collecting achieved by professionals until the end of $20 \mathrm{~s}$, will reduce not just due to the diminution of available snails, but also due to the absence of labor force at competitive prices (Fortier, 1999). Trade is closely linked to the availability of seasonal workers, scrap collectors, various other categories that no longer abandon main occupation to collect snails, either because they can not or are not financially motivated. This is probably also true for the rest of Western Europe. In Eastern Europe however, the poor economic circumstances favor the practice of collecting snails. In Romania, starting from the beginning, collecting land snails was performed by poor, unemployed people, particularly Roma, but also by children from other families, almost exclusively in rural areas. Not just the seasonality of this activity, but also the misconceptions regarding these animals (their slime is considered disgusting and are almost never eaten), made this practice to be considered blamable.

At present, snails are collected especially by Roma, and in some areas, whole communities are involved in this activity every year during April and May. This is the reason why the highest number of collecting centers operates in areas with important Roma population (Gheoca, 2013), making this a social phenomenon. During the last years, the increased number of unemployed people due to the economic crisis has supplemented the snail collectors, generally by temporary basis, but still increasing the pressure generated by collection upon natural populations of snails. As a consequence of collectors' typology, it is very difficult to control the compliance of regulations, especially concerning the snails' dimension. Frequently undersized snails are collected and if rejected by collecting centers, fed to pigs or thrown out, resulting in important mortalities in subadult snails. This can affect the populations already depleted by all the adult snails that can be identified.

\section{SNAIL FARMING IN ROMANIA}

Started in the second half of the 70s, the edible land snail farming (called heliciculture due to the fact that the raised snails are mostly species of the Helix genus) was designed to replace the snails' exploitation in the wild due to the decrease of natural resources and the irregular character of their availability for the developing processing plants. Today in some countries, snail farming is widely practiced as it is the case of Italy and France, but heliciculture did not remain unknown virtually in any of the European countries, be it sporadic attempts or true "snail growth fevers".

Three farming methods were developed: the intensive method, entirely indoor controlled, the extensive method or outdoor and the combined one with breeding, hatching and possibly the first post-hatching growth stages (nursery) in controlled spaces, while the fattening is performed outdoor. The first one, entirely indoor, developed by the French was abandoned, and at the moment the extensive method (the Italian method) and the combined one (the French method) are used.

Romania wasn't exempted neither, as most European countries, from the fever of raising snails. The farming of edible snails has evolved in Romania, especially during the period 2004-2008, when many farmers were attracted by the idea of getting almost immediate benefit with little investment and not much technical effort (fig.1). Some of the farms founded in this period were financed by the SAPARD Program, dedicated to support the efforts being made by the Central and East European applicant countries in the preaccession period, as they prepared for their participation in the common agricultural policy and the single market (fig. 2). The mirage of getting rich was sustained by several foreign companies, advertised by the National Agency for Agricultural Consulting. The contracts signed between the Romanian farmers and different technology and material providers proved to be inconvenient for the farmers who found themselves without a market and production place, already substantially diminished due to the application of an unadjusted Italian method that wasn't purchased by the companies as contracted.

The farms founded by SAPARD Project constitute just a small fraction of the total number of farms established in Romania. Unfortunately, there is no reference about the total number of farms ever existent in Romania. The official 
information regarding the snail farms are divided mostly between two national registers, whereat the farmers were interested to register, the Register of Agricultural
Exploitations and the List of Operators in Organic Agriculture.

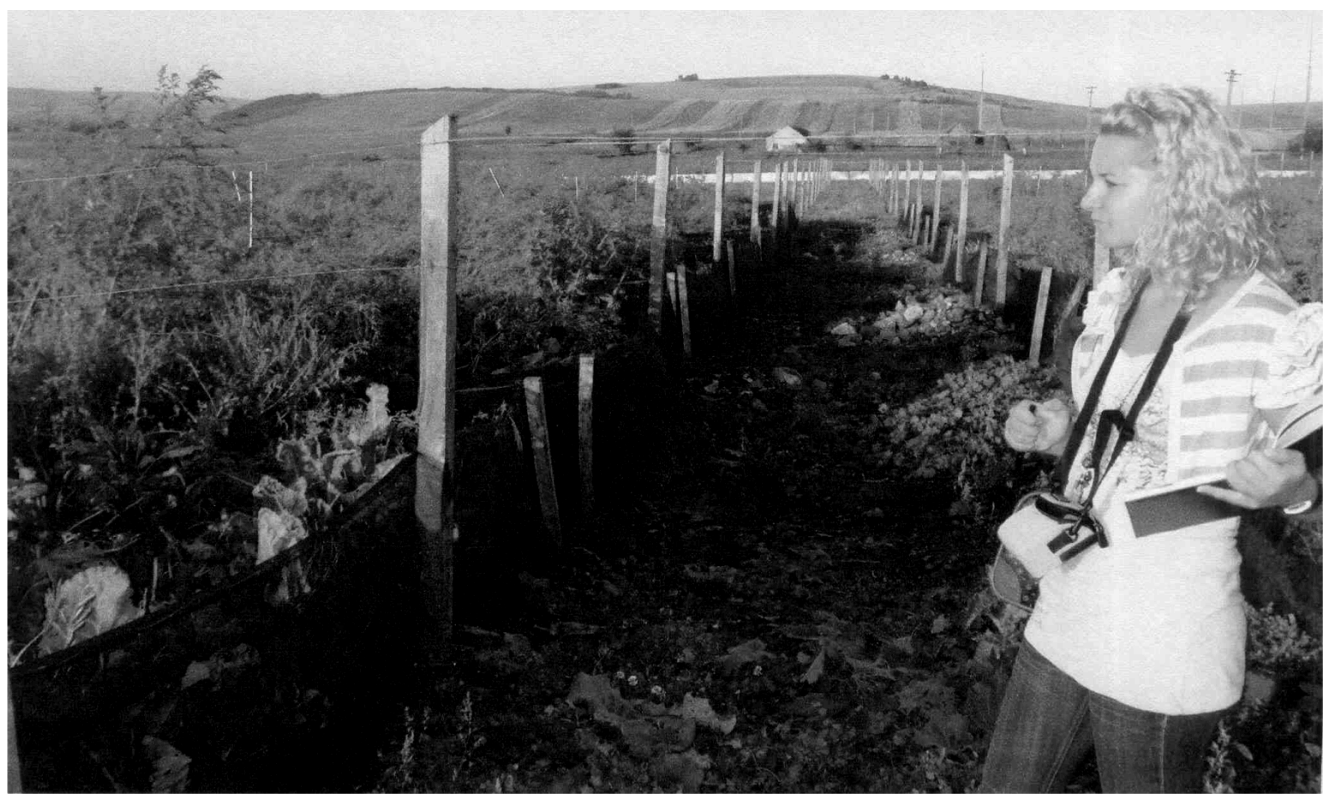

Figure 1. Snail farm in Armeni, Sibiu County, in 2007. The farm, like most of the farms operating in Romania, followed the Italian method: outdoor parks with Helitex closures and plants to feed and shade the snails.

Other numbers are available from other sources. Thus the official site of International Heliciculture Institute from Cherasco, Italy, gave the number of snail farms established before 2010 all over the world using the Italian method. According to their data, Romania was positioned on the fourth place with 164 farms and 130 hectares (table 2). On the other hand, a number of 236 farmers from 31 counties associated in 2005 to build at Teliu (Brasov County) the most modern processing plant from Romania. The snail farms of this association summarized over 100 ha and the plant was designed to process over 300 tones organic snail meat every year. The plant became operational in 2008 and two years later, as a result of poor management, the association was found unable to pay its loans and was declared bankrupt. Subsequently the majority of farmers have given up snail farming, this representing a critical moment in the evolution of snail farming in Romania. This data demonstrate that the official numbers underestimate the total amount of snail farms existent during 2004-2010 in Romania, number unofficially evaluated at over 600 .

The temptation to obtain more valuable organic products prompted many farmers to engage in this direction. But the requirements of European legislation and the legislation of the country of destination for the Romanian products are quite restrictive and difficult to reach. This could be another reason of the collapse of snail farming in Romania. Also, the most often farmed species was $H$. aspersa, which has major problems for wintering in our climatic conditions, and experienced high mortalities during the winter. On the other hand, the autochtonous species $H$. pomatia is more sensitive when enclosed and its farming technique still needs adjustments. Thus, a previous documentation is reasonable to do before starting a snail farm.

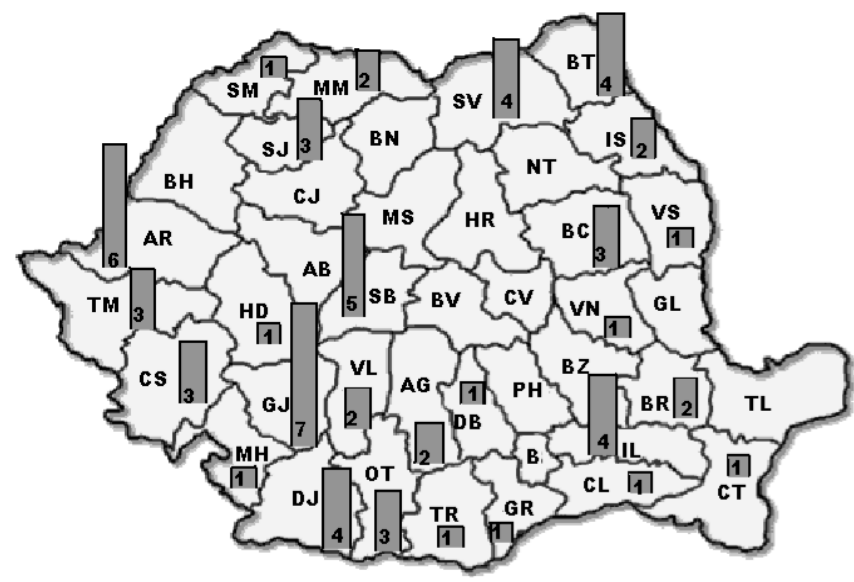

Figure 2. Distribution of snail farms founded by SAPARD Program in Romania (source: Ministry of Agriculture and Rural Development)

Table 1. The number of snail farms using the Italian method set up before 2010 in Romania (source: http://www.lumache-elici.com)

\begin{tabular}{|c|c|c|c|c|}
\hline Countries & No of farms & Surface (ha) & Farmed species & Quality of production (\%) \\
\hline Italy & 4.300 & 5.200 & H. aspersa, H. pomatia & 60 \\
\hline Serbia & 240 & 240 & H. aspersa, H. pomatia & 70 \\
\hline Greece & 200 & 100 & Helix aspersa & 91 \\
\hline Romania & 164 & 130 & H. aspersa, H. pomatia & 45 \\
\hline Bulgaria & 90 & 75 & Helix aspersa & 40 \\
\hline
\end{tabular}




\begin{tabular}{|c|c|c|c|c|}
\hline Countries & No of farms & Surface (ha) & Farmed species & Quality of production (\%) \\
\hline Croatia & 44 & 65 & H. aspersa, H. pomatia & 60 \\
\hline Montenegro & 22 & 7 & H. aspersa, H. pomatia & 50 \\
\hline Albania & 21 & 17 & Helix aspersa & 65 \\
\hline Tunisia & 21 & 18 & Helix aspersa & 65 \\
\hline Kosovo & 16 & 11 & Helix aspersa & 50 \\
\hline Slovenia & 15 & 18 & Helix aspersa & 60 \\
\hline Germany & 6 & 5 & H. aspersa, H. pomatia & 65 \\
\hline Spain & 4 & 4 & Helix aspersa & 70 \\
\hline Hungary & 4 & 7 & H. aspersa, H. pomatia & 40 \\
\hline Czeck Rep. & 4 & 5 & H. aspersa, H. pomatia & 50 \\
\hline Poland & 3 & 5 & H. aspersa, H. pomatia & 50 \\
\hline Argentina & 3 & 32 & Helix aspersa & 70 \\
\hline Russia & 2 & 9 & H. aspersa, H. pomatia & 35 \\
\hline Morocco & 2 & 2 & Helix aspersa & -- \\
\hline Other countries & 18 & 95 & H. aspersa, H. pomatia & 65 \\
\hline
\end{tabular}

\section{POTENTIAL SOLUTIONS FOR THE PRACTICE OF SNAIL FARMING IN ROMANIA}

Although the negative experiences and the apprehension regarding snail farming have discouraged Romanian farmers, we believe that it could be practiced in Romania, following the example of other countries and/ or developing our own model, if we solve some issues that we consider extremely important in starting a business in this area.

Key elements to consider are:

- $\quad$ appropriate documentation on the biology of snails, their ecological requirements and applicable farming systems, as well as an economic analysis;

- the selection of appropriate species is very important and it must regard all aspects starting the species' biology, but also the productivity and the ability to grow in captivity.
- the choice of system growth - important when we try to elevate snails in an area were the winter frost can reach frequently $-20^{\circ} \mathrm{C}$.

- taking into account the intended production/ finished product.

A number of arguments are today in favor of farmed snails, from conservative arguments to economic ones. The taste of farm snails is superior to those collected in nature, given that in the latter the food, the snails' origin and habitat quality (potential pollution) cannot be controlled. Another argument is that snails originating from farms have a regular growth and the exploitable size is reached at a younger age. The meat product will be therefore softer and tastier than that one coming from animals in the wild. On the other hand, the farms allow traceability that can guarantee consumer safety. Table 2 summarizes some advantages and disadvantages of the two practices, exploitation of natural populations and farming.

Table 2. Some economic advantages and disadvantages of the two practices concerning edible land snails, exploitation of natural populations and farming

\begin{tabular}{|c|c|c|}
\hline & Collecting in the wild & Farming \\
\hline Costs & relatively small & $\begin{array}{c}\text { higher or lower initial costs, depending on } \\
\text { the farming system }\end{array}$ \\
\hline $\begin{array}{c}\text { Capacity to supply the } \\
\text { market }\end{array}$ & $\begin{array}{c}\text { discontinuous and dependent on species } \\
\text { availability in nature }\end{array}$ & $\begin{array}{c}\text { can be continuous, depending on the } \\
\text { farming system }\end{array}$ \\
\hline Food safety & $\begin{array}{c}\text { cannot be guaranteed for the animals can } \\
\text { accumulate toxic substances from their } \\
\text { environment }\end{array}$ & $\begin{array}{c}\text { can be secured by controlling the food of } \\
\text { snails }\end{array}$ \\
\hline $\begin{array}{c}\text { Quality of the outcome } \\
\text { products }\end{array}$ & $\begin{array}{c}\text { cannot be controlled, there are dependent } \\
\text { on the available food }\end{array}$ & $\begin{array}{c}\text { can be controlled and can be deliberately } \\
\text { induced by the introduction of aromatic } \\
\text { herbs in food }\end{array}$ \\
\hline Incomes & are discontinuous & can be continuous \\
\hline
\end{tabular}

\section{CONCLUSIONS}

The implementation of management measures should allow the conservation of this species and also maintain local consumption practices. The existence of the legal framework governing the collection is a defining element for the management of natural resources; however we emphasize the importance of law enforcement mechanisms, the correct assessment of existing quantities and taking into account when estimating the potential for gathering of all the elements that can affect the dynamics of the species. Despite the existent regulations, they are not supported by appropriate population and ecologic studies. In this general context, an international concerted action is imposed by ecologic studies, but also by studies regarding the local potential of heliciculture, able to provide a solid foundation of an effective legislation in this regard. This could allow a sustainable exploitation of this locally important natural resource. 
Mismanagement of natural populations by allowing each year the extraction of quantities exceeding the recovery ability of the population could lead to the decline of these species in Eastern European countries where they are still well represented, but where collecting pressure is the highest.

Developing snail farming could be an alternative to the exploitation of natural populations and could also become an important source of income in rural areas. It is unlikely that snail farming will replace collection on short or medium term, but obtaining reasonable quantities of snails in snail farms could help to reduce their exploitation in nature to an acceptable level and keep a sustainable exploitation.

\section{REFERENCES}

1. Adams, W.M. 2006. The Future of Sustainability: Rethinking Environment and Development in the Twentyfirst Century. IUCN [The World Conservation Union] Report:http://www.iucn.org/members/future_sustainabili ty/docs/iucn_future_of_sustainability.pdf,

2. Bonnemain, B., 2005, Helix and Drugs: Snails for Western Health Care From Antiquity to the Present, eCAM 2005;2(1)25-28.

3. Brooks SA, Leathem AJ., 1991, Prediction of lymph node involvement in breast cancer by detection of altered glycosylation in the primary tumour. Lancet 1991;38:714.

4. Cranga, F., Cranga Y., 1991, L'escargot. Zoologie, symbolique, imaginaire, médecine, gastronomie, Dijon, Ed. du Bien Public.

5. Dominguez Valdes-Hevia, M., et al, 2012 Product for the preparation of dermatological, cosmetic or cosmeceutical compositions intendent for skin treatement. Pattent application publication US 2012/0107410 A1

6. Duhart F. 2009, Caracoles y sociedades en Europa desde la antigüedad. Reflexiones Etnozoológicas, STVDIVM. Revista de Humanidades, 15 (2009) ISSN: 1137-8417, pp. 115-139.

7. Dwek MV, Ross HA, Streets AJ 2001. Helix pomatia agglutinin lectinbinding oligosaccharides of aggressive breast cancer. Int J Cancer 95:79-85.

8. Fortier, A., 1999, La réglementation du ramassage de l'escargot: le cas d'Helix pomatia», Le courrier de l'environnement, 38: 75-83.

9. Gheoca, V., 2013, Edible land snail Helix pomatia's exploitation in Central Romania - legislation, evolution, perspectives. în Advances in Environment, Ecosistems \& Sustainable tourism (Marascu-Klein, V., Panaitescu, F.V., Panaitescu, M, eds.), Proceedings of the $11^{\text {th }}$ International Conference in Environment, Ecosistems and Development EED'2013, Braşov, Romania, (ISBN 978-61804-195-1).

10. Lanzman-Petitthory D. 2001. Alpha-linolenic acid and cardiovascular diseases. J Nutr Health Aging 2001;5:179-83.

11. Reza Arab, M., Salari, S. Karimi, M. Mofidpour, H., 2010, Lectin histochemical study of cell surface glycoconjugate in gastric carcinoma using Helix pomatia agglutinin. Acta medica Iranica (Acta Med Iran) 2010 Jul-Aug Vol. 48 Issue 4 Pg. 209-13 ISSN: 1735-9694 [Electronic] Iran. 